\title{
History of Oromo Social Organization: Gadaa Grades Based Roles and Responsibilities
}

\author{
Dereje Hinew \\ Department of History and Heritage Management, College of Social Science, Post Box No: 395, \\ Wallagga University, Nekemte, Ethiopia
}

\begin{tabular}{|c|c|}
\hline Abstract & Article Information \\
\hline \multirow{3}{*}{$\begin{array}{l}\text { The major purpose of this manuscript is to depict how membership to gadaa grades } \\
\text { determined the social-political and economic roles and responsibilities of individuals in the } \\
\text { Oromo society and show the viability of values of Gadaa in democratic culture. The } \\
\text { Gadaa system is a special socio-political organization of the Oromo people that has its } \\
\text { origin in the age-system of the Horn of Africa. In the system, male individuals were } \\
\text { grouped into grades known as gadaa. As an age-based social organization, the Gadaa } \\
\text { system provided the mechanism to motivate and organize members of the society into } \\
\text { social structure. Various socio-political rights and responsibilities are associated with each } \\
\text { group. Accordingly, the system provided a socio-political framework that institutionalized } \\
\text { stratified relationship between seniors and juniors and egalitarian relations among } \\
\text { members of the grade. Initiation into and promotion from one gadaa grade to the next } \\
\text { were conducted every eight years. The fundamental quality of the Gadaa system is that it } \\
\text { has segmentations and specified social functions for its members that helped the } \\
\text { members to develop a consistent and stable sense of self and others. }\end{array}$} & $\begin{array}{l}\text { Article History: } \\
\text { Received : } 12-07-2012 \\
\text { Revised }: 22-09-2012 \\
\text { Accepted }: 30-09-2012 \\
\end{array}$ \\
\hline & $\begin{array}{l}\text { Keywords: } \\
\text { Oromo } \\
\text { Social organization } \\
\text { Gadaa } \\
\text { Luba } \\
\text { Gogeessa } \\
\end{array}$ \\
\hline & \\
\hline
\end{tabular}

\section{INTRODUCTION}

The Gadaa system was the constitution of the Oromo society through which the society administered, defended their territory, maintained and developed their economy. Even though the tradition was reduced to social aspect following the incorporation of the society into the Ethiopian state, the system influenced every aspect of Oromo society, from politics to religion until recently.

The Gada system comprised eleven age groups, based on eight-year increments, and male Oromo gained particular socio-political privileges with certain stages of the Gadaa system (Baxter, 1979). Five successive gadaa stages make up a generation (gap between father and son) that occupies forty years on the gadaa cycle. The first five eight years were generally periods of training and military service in addition to shouldering some economic activities. The remaining gadaa grades consists of the adulthood stages that continues up to the eleventh stage. The stages of adulthood were periods of socio-political responsibilities.

An individual entered the system at a specific age and passed through transition rites at intervals appropriate to the passage from childhood through full adulthood to senility. Recruitment in to the Gadaa system is based on the maintenance of one socially defined generation between father and son (Asmarom, 2000; Asafa, 2010). In other words, enrollment into the system is not by biological age, but upon the recruitment that an individual remain exactly five stages below his father's level. Gadaa grades succeeded each other every eight years enjoying privileges of the stage and assuming military, economic, political, and ritual responsibilities of the society (Asmarom, 1973). Among the Oromo the concept of gadaa has three related meanings: a socio-economic, political and religious institution; it is a period of eight years during which elected officials assume power; it refers to the class of people in power holding sociopolitical leadership. 
Dereje Hinew

Gadaa system is one of the main themes studied by scholars of different disciplines. Scholars that studied Gadaa system at large gave attention to the nature of the institution, the socio-cultural performance in Gadaa system, calendar, and the political aspect of the Gadaa system. Asmarom produced the most comprehensive ethnographic study on the indigenous Oromo socio-political organization based on the people's oral historic records (Asmarom, 1973). However, none of the scholars studied the age-grade privileges and responsibilities of individual members and clearly depicted the training, knowledge acquired and the rights and duties attributed to the members.

\section{MATERIALS AND METHODS}

The absence of a written language of the Oromo negatively affected the development of Oromo studies. For long Oral tradition had not been accepted as authentic historical source. However, since 1960s in Africa and in Ethiopia as well a critical use of oral sources (especially oral traditions) has made the reconstruction of people past possible. Many scholars have made a tremendous effort to reconstruct the history and culture of this society. By using these new methodologies, scholars have focused on the studies of different themes. Oral tradition is resourceful historical source that refers to human actions reported through speech and handed down from generation to generation. A critical use of Oral traditions helps scholars to reconstruct history of certain theme.

The data in this study consisted of the written and oral sources. In the category, the attempt was first started with reading written data in which both historical and anthropological studies are very important. This was followed by conducting field research among the Borana, Guji and the Tulama Oromo, which preserved the Oromo culture. This method provided me indispensible data to study Gadaa system. The data were gathered through interview and discussion with Oromo elders. Oral traditions of the society collected at different time also contain and provide much information on the subject under the study. In addition, Gadaa system provided the society with a unique method of time computation and the method of transmitting history known as argaa-dhageettii (from what they heard and saw). The chronology and records of events based on the gadaa calendar that provided the society to retain their past also is a dependable source of data for concerned scholars.
Sci. Technol. Arts Res. J., July-Sep 2012, 1(3): 88-96

\section{RESULTS AND DISCUSSION}

Studies associate the origin of the Gadaa system with the culture of ancient African societies. The Afro-Asiatic societies (Afrasan) are said to have had broadly shared ideas, practices and beliefs because of their common historical root and long period interactions (Ehret, 2002). Haberland argued that age-grade system was exclusively associated with eastern Cushitic peoples. He indicated that the cultures of Cushitic or Nilotic had certain common cultural elements of per-Islamic Arabia and ancient Israelites. Moreover, he mentioned that certain concepts of the 'old testament' type, which were original and fundamental elements of their culture were found among the Cushitic, including the Oromo. Based on these cultural similarities, Haberland suggested that the Oromo, Sidama, Hadiya, Konso and Tsamako might have common origin whose dissemination had been in the ancient time (Haberland, 1963). Similarly, Lewis argued that the eastern Cushitic speakers such as the Afar, the Oromo, the Somali, the Saho, the Konso and others were linguistically, culturally and historically linked. Their separation is said to have taken place around 3000 to 4000 years ago (Lewis, 1966). These Cushitic peoples are said to have lived in the central Ethiopian plateau and were differentiated into subgroups, and the Oromo had been one of such groups. Besides, the home of these Cushitic peoples is said to have been the northeastern and eastern Africa. Specifically, Nubia (the land of Kush or ancient Ethiopia; the middle and Lower Egypt) was from where most probably Cushitic peoples dispersed and formed separate linguistic and cultural groups (Gada Melba, 1988). Ehret added that around the seventh millennium BCE (before Christian era) the ancestral Cushitic began to spread in the northern edge of the Ethiopian highland. The proto-Cushitic is said to have formed various subdivisions and dispersed further south in the sixth and fifth millennium (Ehret, 2002).

Regarding the special organization in east Africa, Asmarom argued that the Gadaa system of the Oromo developed out of a common east African institution of age-set that was practiced by the Cushitic, the Bantu and the Nilotic peoples (Asmarom,1973). Some scholars also argued that the basic similarity of generation grading system was the reflection of the close proximity of societies and their common origin (Hallpike, 1976). Haberland indicated that due to the long period of interactions, almost all the eastern Cushitic language-speaking peoples had Gadaa 
Dereje Hinew

system in their own social structure (Haberland, 1963).

Nevertheless, Haberland stated that the Oromo culture was archaic and extremely simple and suggested that the complicated nature of the Gadaa system of the Oromo made it to appear a foreign element. In fact, any society does not appear with fully operating social institution. The social, political or religious institution of any society grows out of an archaic and very simple ideas or philosophy. Ideas or concepts could evolve, develop and be modified. As indicated above Gadaa was an ancient Oromo term, which stands for era and has later come to represent different meanings (Tesema, 1980). There is no reason why the Oromo could not evolve their own complex social organization and build up into complex socio-economic and political institution. It is not clear why the Oromo were not credited as inventor of unique culture or having socio-political institution that flourished in patterns of their own history. In fact, Haberland did not identify from which society the system spread or which society influenced the other and he did not also convince us or made us know the origin of the system.

Trimingham contradicted with himself by arguing first; the originators of the Gadaa system were the former Bantu inhabitants of Somalia and later by stating that the Gadaa system of the Oromo must have its origin in the age group of the 'Hamatic' Nilotes (Trimingham, 1976). On the other hand, it is said that the system spread to Nilo-Hamites and the Bantu from the Oromo. The Masai, the Gedeo, Nandi and Konso are said to have adopted their Gadaa system from the Oromo (Beckingham and Hunting ford, 1954). Nevertheless, the Oromo is the one that developed the system into a more complex institution (Asmarom, 2000).

The Oromo Gadaa system is unique in developing the use of generation called gogeessa (forty years gap between father and son) as an element of its organization (Asafa, 1993). The Oromo might have shaped and modeled the system based on their own internal situation after they formed their own social entity. In fact, both internal and external factors forced a society to change and modify its social structure. Such type of social organization might have begun when the society needed to sustain social order among themselves and to defend their rivals that were competing with them for land, water and power (Asafa,1993). It might have begun also when the concept of common descent, the concept of peace and cooperation among the
Sci. Technol. Arts Res. J., July-Sep 2012, 1(3): 88-96

society developed. These concepts together could express some deep sense of solidarity and feeling of people hood (Baxter, 1978). From the beginning, a principal purpose of Gadaa seems to have been to maintain a united strength against other groups and peaceful life within the society (Baxter, 1978). In its early days, Gadaa system is said to have been purely a social institution that helped the society as a constitution that helped the society to avoid subordination and exploitation. Social organization was important for a people to exist as a society and for the division of labor (Asmarom, 1973).

According to Ehret, the intensification of Agriculture in the rift valley areas of the Ethiopian highlands and the increase in population between 3500 and 1000 BCE had resulted in the changes of the old social and political institution. It is said that in the other parts of the world when the demographic increase led to state formation, in the Ethiopian rift valley region a sharply different method of providing social cohesion age-set system came into being. This system is said to have began first in the Konsoromo society (eastern Cushitic) no later than some time in the second millennium BCE. By the time, Ehret argued, among the Konsoromo the cycle repeated itself every eight years and new groups were initiated in a ceremony held every eight years (Ehret, 2000). Based on recent archeoastronomic research, Asmarom also argued that some aspects of Gadaa culture especially the astronomic calendar goes back as far as the second century B.C (Asmarom, 2000). Such investigations tell us that the system was an ancient institution in east Africa. Therefore, it appears that Gadaa initially emerged for governance, social cohesion just as state formation did a similar thing in the other parts of the world. The Gadaa system guided the Oromo religious, social political and economic life for many centuries. Asmarom, who studied the Gadaa system in detail, argues that it is a system of classes that succeed one another every eight years in assuming military, economic, political and ritual responsibilities (Asmarom, 1973). In its nature Gadaa is similar to the Greek age set system that assigned training and duties to men of (1-18 years) music and literature,(18-20 years) physical strength, (20-30 years of age) mathematics and other science, (30-35 years) dialogue and ethics,(35-50 years) law and giving service and above 50 years philosophy(Alemayehu, 2009).

In the Gadaa system, generation, age, sex, and class were the guiding criteria in labor division and the sharing of responsibilities. It is 


\section{Dereje Hinew}

obvious that, Gadaa based division of labor and the allocations of functions were a socially and culturally constructed phenomenon in conformity with the overall general property relations (Alemayehu, 2009:168; Negaso, 2001:125). Principal variables as age, sex etc were ways of group formations, differentiations along with role assignments among diverse social groups.

Despite its egalitarian nature, Gada effectively enforced a gender-based division of labor in Oromo society and excluded women from passing through age-sets and generation-sets. The tough, physical labor and muscular demanding nature of the Gadaa system, a compulsory requirements for muscularity to be stayed at Gadaa centers and being deployed on hunting for military training for a long distance away from residence and similar factors seemed to be some of those main reasons to give opportunities to male. Gadaa demands tough military and hunting exercise activities and fitness, which a female being is thought to be unfit, ascribed to females' nature for life-giving quality along with the then prevalent socioeconomic, geo-political, environmental, ecological, etc variables (Ginbar, 2011). Hence, gender oriented labor division seems to be logical, scientific and reasonable factors associated with the nature of the task, the ability of the performer, profession and other internal and external conditions. Nevertheless, it is unfair and blind accusation to judge simply the past society had established a functional discriminatory institution whereby female identities were oppressed.

Gadaa system functioned along the lines of Oromo knowledge of the society and the world that includes the customary (bekumssa aadaa) and knowledge of law. The latter is further divided in to law of God (immutable) and law of human beings. Oromo cultural and customary laws are common and public knowledge that regulates the activities of members of the society (Asafa, 2010).

It is natural that people of the past had their own formulated simple or complex institutions, means and methods approaching natural and social circumstances at their surroundings. Given that socio-cultural and ritual mechanisms were often used to approach their world, resolve dilemmas at their environment, social inventions were parts of numerous apparatus a given society address and communicate the natural world (Ginbar, 2011). Women had the Siiqqee institution, a parallel institution to the Gadaa system that "functioned hands in hand with
Sci. Technol. Arts Res. J., July-Sep 2012, 1(3): 88-96

Gadaa system as one of its built-in mechanisms of checks and balances. These two institutions helped to maintain Safuu (moral and ethical order) in Oromo society by enabling Oromo women to have control over resources and private spaces, social status and respect, and sisterhood and solidarity by deterring men from infringing upon their individual and collective rights (Kuwee, 1991).

The age- set system was a segmentation that maintains specialization of function along effective lines. It harnesses the energies of the youth to the end of the society and gives to each age group a strong awareness of its own status. The Gadaa system, as an age-based social organization must have also been developed as a mechanism of motivating and fitting members of the society into social structure. Accordingly, various socio-political functions and responsibilities are associated with initiation into and promotion from one gadaa to the next. The structural elevation follows an established procedure. Members of an age- set are initiated into the next higher set with elaborated ceremony. The initiation obviously gives and imposes responsibilities on the elevated groups. The age- set system provided clear structural reference for members of the society so that the society developed a consistent and stable sense of self and others (Jeylan, 2005). The division was parts of the entire aspects of their interdependent living.

Gada system served as a base of democratic and egalitarian political system. The system is self-sufficient system, which has influenced every aspect of Oromo's life. A system organizes the Oromo society into groups that assume different responsibilities in the society every eight years. There are five active and five passive grades in a cycle of forty years (Figure 1). The five gadaas in the cycle have names that vary slightly from region to region. This must not be confused with the names of the five-gadaa parties, which again have different names at different areas.

\section{Gadaa Grades and Major Privileges and Responsibilities of Members}

In the Oromo social life, Gadaa system assigned rights as well as obligations to all the males in the society. Activities and social roles are formally defined, both in terms of what is permitted and in terms of what is forbidden (Tadesse, 1995). Among other functions, the separation of men into grades is a division of labor. Individual male as part of a permanent group, contributed his labor power in different 


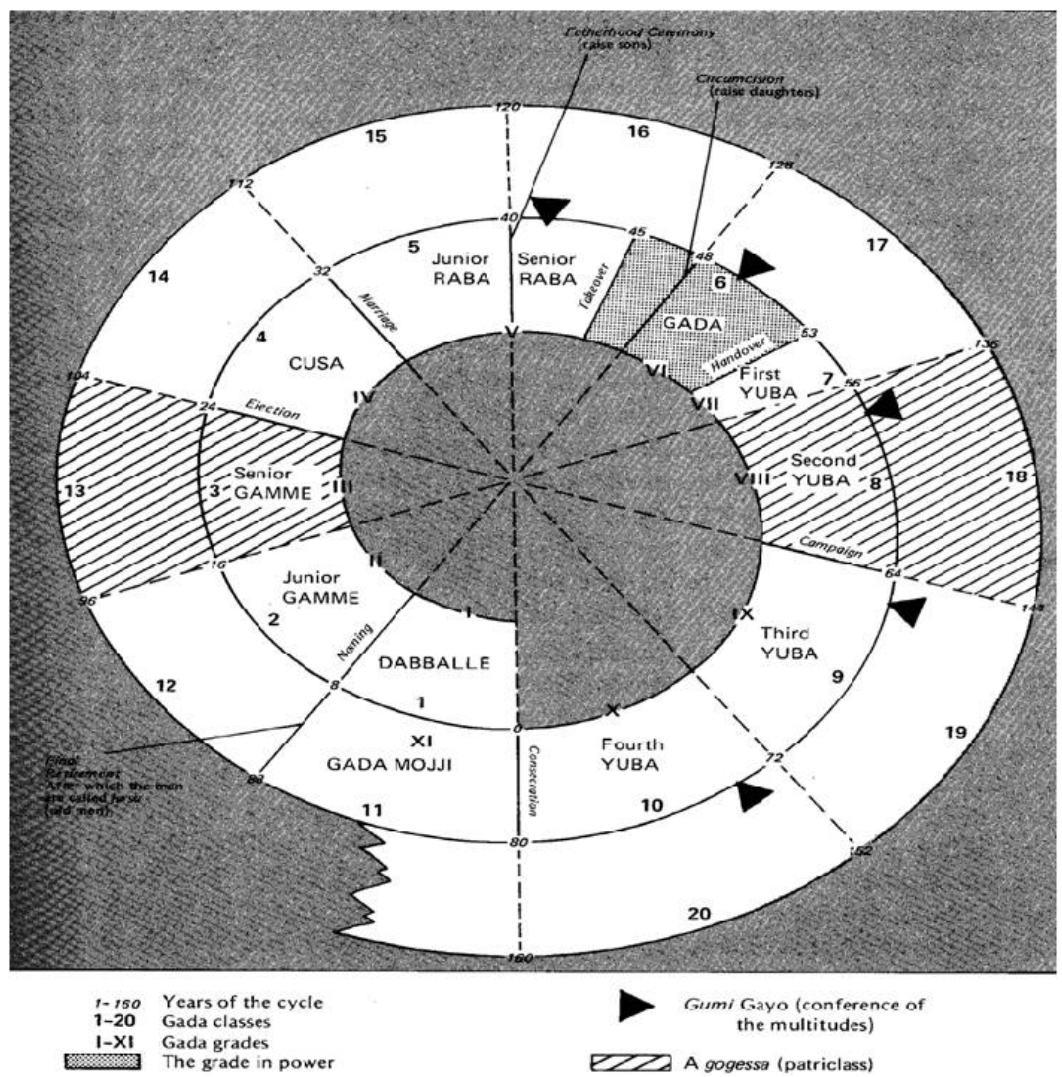

Figure 1: Five active and five passive grades in a cycle of forty years (Source: Asmarom, 1973)

capacities to the society as a whole and was prohibited from settling permanently until he had completed the cycle. The grades were also periods of initiation and training as well as periods of work and performance. The most important element that regulates the Gadaa system is the responsibilities and rules attached to the age-grade system. Every Oromo of specific age-grade is expected to perform a certain function according to specified rules and regulations. Hence, by leaning the customary law and law of Waaqaa, every person was expected to contribute to the social development. Social development (finna) stands for " the legacy of the past which each generation inherits from its forefathers and which it transforms; it is the fertile patrimony held in trust by the present generation which it will enrich and bequeath to future generations..."(Asafa,2010). Hence, in the system as Martial De Salviac stated, "...the Oromo child, imbued with principles and rules of conduct, becoming philosopher without school, eloquent without rhetoric, soldier without enlistment, lawyer without code ... advance with steps in the accomplishment of his duties..." Ayalew, 2007). The gadaa grades and the socioeconomic and political duties associated with the grades are as follows.
1. Ittimakoo/daa'imman (0-8): The name refers to and has the meaning "He (Waaqaa) added them to the people." They were born, ideally, when their fathers' gadaa set is in office. As the members are immature and hence are considered as holy children and source of blessing (Desalegn, 2005). Among the Borana this child hood is known by the name of Dabballe. Asmarom noted, "dabballe are among the principal mediators between men and God invested with powers and attributes similar to Kallu" (Asmarom, 1973). Before the maqbaasa (name giving) ceremony, they were not given real names, and they were still between Waaqaa and their people (Bartles, 1990). The members were identified with their amazing hairstyle known as Guduruu/gaammee, which was a symbol of childhood. This grade was known as socialization age into the society and the Gadaa culture (Lemu, 1971). Just as girls, they were privileged in the society in that families and members of the society were expected to love, give attention and protection to them (Asmarom, 1973). The family had to show witness of their affection for the calm and sensible spirit. Customary law prohibits their parents from punishing them physically. Families (especially mothers) were expected to sing cultural songs that praise children of this age. As the Dabballee were immature, no specific political 
Dereje Hinew

roles were associated with them. At initiation ceremony to the next gadaa grade, they had hairs shaved off to remove all the bad things of the childhood symbolizing to have another identity.

2. Dabballee/Junior Gaammee (9-16): The ittimakoo were admitted to the gaammee grade and the mainstream of the Gadaa system with initiation ceremony, which was a turning point for Dabballee's father and grandfather. Dabballee's father got full status in the Gadaa system as the ruling gadaa group while the grandfathers retired from the Gadaa system. Initiation into Dabballee grade was followed by Maqbaasa ceremony in which members were given individual and group name, which was one of the names of five-gadaa parties. This stage was mainly a period of socialization process when the members were equipped with the historical and cultural tradition of the society as well as beginning military training (Lemu, 1971).

Members of this age and girls commonly called sookkee (early teen-age) were required to learn counting numbers with analogies and genealogy on fathers and mothers line. This age a fertile time to study Oromo myth, riddles, stories of different types, geerersa, cultural songs. (Jabessa, 1970)The contents of training at this stage is civic related subjects to inculcate in the minds of children certain societal values of the people such as respect and dignity for humankind, accountability and responsibility to the community, patriotism and love for the fatherland, and family identity and history. Some methods of instruction were war songs known as geerarsa and faarsaa (praising). In such away elders taught them by tracing the family lineage several generations back and narrating story of historical events in society such as major battles fought; natural disasters (drought, epidemics, and crop failure); migration etc (Melaku,2001). In this regard, boys of this age were provided with instruction in Oromo ethics and societal values. Some of the topics covered in this area revolve around the concepts of family, values of teamwork, resource sharing, community interactions, justice, and loyalty to the rule of Gadaa (Alemayehu, 2009).

Even though training on critical thinking was not limited to this stage, probably, the main contribution of traditional Oromo education to children of this age was in the area of mental (cognitive) development. Girls were key role players in playing puzzles and Hibboo (riddles). Riddle was the most commonly used instructive technique in the development of critical thinking.
Sci. Technol. Arts Res. J., July-Sep 2012, 1(3): 88-96

Other than its significance in developing the mental capacity of children, riddles entertained the young learner by presenting things in different perspectives.

There were no political obligations attached to the gaammee xixiqqoo as a gadaa grade. However, they had to assist their families in domestic life according to their capacity. Besides, they also practiced some hunting related games like throwing spear through moving circular object known as geengoo (Melaku, 2001).While tending their animals; they also practiced racing competition, long jump and high jump, running over hurdles. In such away, they acquired the quality of muscular strength and accuracy for the future career.

3. Foollee /senior Gaammee (17-24): The term Foollee was derived from foolachuu, which means to be excited that reveals members as teenagers. This is the most important stage in the gadaa cycle when the members shoulder family responsibilities and engage in military training. In other words, this period was the period of excitement and military training. In domestic life, they engaged in how to prepare and use plowing materials in agriculture, utilization of property, family management and social life by observing the aadaa (culture) and seeraa of the society. Young boys of this age were also encouraged to work and keep property for their future life. This is why most of their geerarsa convey the quality of hard working and being self-sufficient abhorring poverty life. They were expected to know the custom, habit, tradition, and way of life of the society and obey the laws of Gadaa system. The members guard the Luba (men in power) and mostly included in military service under the leadership of Abba duulaa (war minster) (Dereje, 2000). The Foollee had to develop a quality and capacity of fighting against injustice at least in their clan.

Every Foollee except with special physical cases was required to train how to fight and hunt. The crucial practices in training were horse ridding for cavalry. It is customarily mandatory for military experts to train members of this stage. Horse fighting and horse riding games were the most important part of Oromo military skill. Therefore, the future cavalry in the military segment had to be trained at this stage. This includes the use of horse in fighting, spear throwing, handling of shields and defending the group to be fought (Jabessa, 1970). They obtained military campaign tactics and fighting from their immediate senior stage and military gadaa officials. The training was supported by 


\section{Dereje Hinew}

recitation of military achievement of brave men. Most of the time, they were engaged in body building exercise and wrestling with their agemates and practicing gorilla fighting. At the end of the grade for three years, the members were taken to remote areas for apprenticeship where they involve in hunting wild animals or other target for test of competency. The failure to demonstrate the required model of training has no excuse after which the members were assigned to perform other activities. Success in the apprenticeship was considered as the greatest achievement of the stage. Although hunting wild life is illegal today, killing elephant, rhinoceros, buffalo and lion accounted for forty, thirty, twenty-five and twenty percent respectively in the test for competency. Buttuu, a special military regiment (those who snatch) were recruited from such successful gallant fighters. The Buttuu were capable of multi-dimensional tactics by the use of horse, gorilla and face. Towards the end of this grade, members were required to show the mock of the warfare the presence of gadaa officials.

4. Kuusaa /Raabaa)/Qondaala (25-32): This was a matured stage for formal military service under the direction of the Abbaa duulaa (Lemu, 1971). The kuusaa were attached with dual tasks in the society: military service and training for gadaa leadership. As junior warriors the kuusaa were purely fighters categorized into sections of cavalry, lafoo (soldiers) and Buttuu (special fighters). The members of this group continue undertaking military training of the earlier grade. The Abbaa duulaa and senior warriors trained this class advanced military talent like wrestling, miliqqee (skill of defending attack) and other skills (Jabessa, 1970). Martial De Salviac described the Oromo military strength as follows "The Oromo is animated with warrior spirit in the highest quality. The vitality and durability of this people, who have traversed centuries, maintain its autonomy and integrity of its custom are due to the courage, to the bravery, to the energy, which it deployed in the struggle "Ayalew, 2007). The military organization of the Oromo is said to have made the people one of the strongest ethnic groups in the Horn of Africa between the twelfth and nineteenth centuries (Asafa, 2010).

In Gadaa system, both male and female of this age were considered as matured group for social responsibilities. According to rakoo (marriage rule), only girls of three gadaa periods (twentyfour years old) were allowed to marry. This seems to have been significant in family planning by controlling early marriage and family related problems among the Oromo. For both male and
Sci. Technol. Arts Res. J., July-Sep 2012, 1(3): 88-96

female sexual intercourse before marriage and social evils like rape and alcoholic addiction were strictly forbidden. Male of this gadaa stage were not allowed to marry and have children as they were serving the nation as military force. The logic behind is the fact that if they died in fighting, the family would be at risk. Hence, to control social justice, they did not have this social privilege until they accomplished military service for eight years. Therefore, each man fought as free man but with passionate as reported by Bahrey the... \{Oromo\} went to war either to kill or die." (Tesema, 1980; Mohammed, 1990).

On the other hand, one aspect of involvement of Kuusaa in politics was voting. As opposed to modern democracy, the optimum age of voting in Gadaa system was the Kuusaa stage (at least twenty-four years of age). Members of this grade elected the future nucleus of Gadaa leaders (Adula councils) among themselves. Gadaa officers of this batch were elected when gaammee to kuusaa passage rites was performed. Hence, for the next sixteen years, the Adula council continued taking training and accumulating experience on gadaa leadership. The candidates were made to physically participate in gadaa leadership and gain knowledge in their stage and the next gadaa grade. The ruling lubaa group assigned experts to train and council the kuusaa in the importance of leadership, organization, and warfare at remote areas separately from society. In such away, they exercised challenges and took lesson how to overcome the expected problems (Dereje, 2000). Geerarsa (war song), proverbs and cultural and historical maps, as well as other social skills that they could use in public speech to praise heroes were also part of their trainings. They also practiced the art of public speaking (oratory) Asafa, 2010.

5. Raabaa /Doorii (33-40): the dooroma means the candidates as they were planning to take power in the next gadaa period. Members of this grade were identified as senior warrior. The remarkable stage at which individual Oromo gained art of leadership and philosophy was the Doorii stage. In addition to serving as senior warriors, members were required to be trained in Oromo calendar, the planetary system, and the details of major public holidays. The Oromo have a unique time reckoning system designating seven or eight of the myriad bodies of the sky, using static nature of the celestial spheres and the movement of the earth with the moon to define the length of the year and the months (Melaku, 2001). 


\section{Dereje Hinew}

The stage was also a period of preparation for leadership to take over power from the exiting lubaa or gadaa leaders. The competency, achievement and recorded contributions at both kuusaa and Doorii stages accounts more in the election to be gadaa official. Hence, they served as apprentices to the ruling council, elected leaders from their own group at the former grade, and prepared to take over power. They observed the ruling council, attended their meetings nevertheless were not given any decision-making opportunity until the formal transfer of power at the end of this stage (Lemu, 1971).

One of the social privileges associated to the dooroma was performing marriage but they were not expected to have children mainly at early years of this stage because generation gap with their son would be violated and the children could not act as senior councilor if they were not born at the right time into the gadaa cycle (gogeessa). Children that were born to before their fathers' initiation to Lubaa grade were referred as ilmaan Jaarsaa that were reduced to a hiriyyaa (peers) group and involved in the gadaa administration only as Jaldhaaba (police).

6. Gadaa /Luba (41-48): it refers to men that accomplished all the five stages and then graduated. This is the optimum age of having maturity, skill and capacity of shouldering and discharging societal responsibilities. The most significant stage in the political life of Oromo males came when they entered this stage, in which they gained full privileges and acted as the political leaders (Jabessa, 1970). At the transfer of power, the members held ceremonies and became the ruling party for a period of eight years. Its leaders exercised full decision-making power and responsibility regarding military and civil matters. When the new leaders were entrusted with defense and governance of their society, the leaders of the previous miseensa retired into an advisory role (Lemu, 1971).

Gadaa officials of different positions were recruited from this miseensa based on the recorded competency of the former gadaa grade. The lubaa were the matured (hayyuu) knowledgeable class that stared leadership with the ceremony known as hand over of bokkuu (baallii) power transfer.

Initiation in to the grade was marked by a buttaa ceremony in which war would become a ritual obligation for the Gadaa classes and successful warriors celebrated these rites of passage with special honors (Melaku, 2001). The purpose of the buttaa war was to show the ability
Sci. Technol. Arts Res. J., July-Sep 2012, 1(3): 88-96

to consolidate the people both militarily and organizationally of the gadaa assuming power (Mohammed, 1990). Bravery was almost worshipped as a religion among the Oromo and therefore, war was intended for fame and to transmit their honorable name for future generations (Melaku, 2001).The Gadaa administrative council consisted of twelve officials as in Borana or nine officials (Saglan Borana) the Macca and Tulama Gadaa leadership. The term Abbaa refers to title of ownership of the position.

The executive branch of Gadaa leadership consisted of a president (Abbaa Bokkuu) or the father of scepter, who had a cabinet of ministers (the hayyuu council) and two deputy presidents. A council, known as shanee or salgee, and retired gadaa officials, also supported the Abbaa Bokkuu. The office of Abbaa Bokkuu or Abbaa Gadaa also dealt with issue of highest importance, the declaration of war, the conclusion of peace, the making of laws, the settlement of disputes within the Oromo society and their neighbors. The highest level of institution of natural resources management regarding water, land and forest was also headed managed under this office (Jabessa, 1970). Abbaa Duulaa (the defense minister) also one of the leading figures in the gadaa government. He was the leader of Qondaala (army) and was elected by the people. His main responsibility included assisting the Abbaa Bokkuu, especially during the time of war. The legislative, the caffee (parliament) was headed by a prime minister (Abbaa Caffee) passed laws and had a spokesperson (Abbaa dubbii), who proclaimed the laws that the parliament passed. Finally, a judicial branch of government judge (Abbaa alangaa) who enacted the legislation passed by the parliament (Asafa, 2010).

7. Yubaa I (49-56), Yubaa II: (57-64), Yubaa III: (65-72) were generally advisors of the gadaa government and educators of the gogeessa. They received a great deal of respect as wise experienced authorities and repositories of law (Jabessa, 1970).

8. Gadaamojjii: (73-80): senior advisor that were distinguished by conducting series of sociocultural ceremonies and rites.

9. Jaarsa: (above 80): phase of old age that has to be cared. Gadaa rules enforce the close relatives and the society to care individuals of this age. Members of this group biologically might not be strong enough and productive. These were fathers of men in gadaa ruling class and grand fathers' of ittimakoo. The members were 


\section{Dereje Hinew}

considered as holy like the newborn babies because babies were on their way from Waaqaa to the Society while the Jaarsaa were on their way to return to Waaqaa.

\section{CONCLUSION}

Gadaa is an indigenous socio-political democratic system of the Oromo people that regulated Political stability, economic development, social activities, cultural obligations, moral responsibility, and the philosophy of religious order of the society. The political philosophy of Gadaa is based on three main values: terms of eight years, balanced opposition between parties, and power sharing between higher and lower levels. Hence, gadaa consisted of five-fixed party system. Every male Oromo passed through eleven series of grades acquiring various talents and skills. The former six grades were fixed learning grades while the latter five grades were educators. Each Grade was associated with various privileges and responsibilities. The system made members of the society to accomplish their obligation and enjoy privileges at the right time. In other words, the Oromo were able to govern social, economic, military, political and other aspects of their life by this egalitarian system. Since Gadaa was highly endowed with moral and legal values, among the Oromo it created peaceful setting and kept social order by prohibiting injustice, social evils, and political chaos. Above all, it discouraged early marriage, banned social evils like corruption and rape and encourages good governance, work and to be self-reliance, that in turn promote development. Indigenous socio-cultural values of Gadaa such as endeavor for self-reliance, tolerance, respect, equality etc could be viable in modern politics if they are promoted.

\section{REFERENCES}

Alemayehu Haile. (2009). Gada System: The Politics of Tulama Oromo. First Edition. Oromia Culture and Tourism Bureau. Volume1.
Sci. Technol. Arts Res. J., July-Sep 2012, 1(3): 88-96

Asmarom Legesse. (1973). Gada: Three Approaches to the Study of African Society. New York: The Free Press.

Ayalew Keno. (2007). The Oromo: An ancient people of the Great African Nation

Baissa Lemmu. (1971). The Democratic Political System of the Oromo of Ethiopia and the Possibility of its Use in Nation Building." George Washington University: M.A.. Thesis.

Baissa Lemmu. (1994). Gada Values: Building Blocks of a Democratic Polity. The Journal of Oromo Studies 1(2): 47-52.

Bartles., Lambert. (1990). Oromo Religion, Myth and Rites of the Western Oromo_of_Ethiopia. An Attempt to Understand. Dietrich Reimer Verlag: Berlin.

Baxter P.T.W. (1979). Boran Age-Sets and Warfare. In: Senri Ethnological Studies.

Baxter, P. Hultin, J and Triulzi, A. (1996). Being and Becoming Oromo Historical and Anthropological Enquirer, Lawrence: The Red Sea Press.

Dereje Hinew. (2005). Historical Significance of Some Major Gadaa Centers in Oromia. Addis Ababa University School of Graduate Studies.

Desalegn Chemeda., Edossa., Mukand Singh., Babeland. (2005). Indigenous systems of conflict resolution in Oromia, Ethiopia International workshop on 'African Water Laws: Plural Legislative Frameworks for Rural Water Management in Africa', Johannesburg, South Africa.

Dinsa Lepisa and Abba Jobir. (1975). The Gada System of Government" Addis Ababa University: LLB Thesis.

Ginbar Nagara. (2011). The concepts of gender ideology in Oromo world view" The proceedings of the third national conference on "research for quality and relevant education and training RVUC, Volume 3.

Kuwee Kumsa. (1991). The Siqqee Institution of Oromo Women. Journal of Oromo Studies 4(1\&2).

Mohammed Hassen.( 1990). The Oromo of Ethiopia. A History, 1570-1860. Cambridge University Press. 